\title{
Effects of a change in the direction of view to near uncorrected visual acuity following implantation of monofocal intraocular lens
}

\author{
MARKÉTA ŽÁKOVÁ ${ }^{1}$, MARTIN FƯS $^{1,2}$, JÁN LEŠTÁK ${ }^{1,2}$ and ŠÁRKA PITROVÁ ${ }^{1,2}$ \\ ${ }^{1}$ CTU in Prague, Faculty of Biomedical Engineering, 27201 Kladno 2; \\ ${ }^{2}$ Eye Clinic JL FBMI CTU in Prague, 15800 Prague 5, Czech Republic
}

Received January 24, 2019; Accepted March 13, 2019

DOI: $10.3892 / b r .2019 .1203$

\begin{abstract}
The objective of the present study was to evaluate the effect of the direction of view of the eye on the postoperative near visual acuity of patients with monofocal intraocular lens. A total of 121 eyes in which we performed conventional cataract surgery with implantation of a monofocal lens were included in the study group. The postoperative examination of near visual acuity was performed at two different positions of the eye at a constant distance from the reading table, with the assumption of improving visual acuity when looking perpendicularly to the plane of the floor. The mutual relation of the postoperative parameters central keratometry $\left(\mathrm{K}_{\mathrm{c}}\right)$, keratometry in the visual axis $\left(\mathrm{K}_{\mathrm{VA}}\right)$ and anterior chamber depth (ACD) for the single axial length ranges was determined using the correlation coefficients. In the case of vertical position of the eye (visual axis of the eye perpendicular to the floor), the uncorrected visual acuity following implantation of the monofocal lens was higher or equal compared to the horizontal position of the eye (visual axis of the eye parallel to the floor). The mean visual acuity at the horizontal position of the eye was 0.508 according to Jaeger's tables $(\mathrm{P}<0.001)$; at the vertical position, the mean value was $0.555(\mathrm{P}<0.001)$. Within the entire group, a weak association at best was observed between the postoperative parameters $\left(\mathrm{K}_{\mathrm{c}}, \mathrm{K}_{\mathrm{VA}}\right.$ and $\left.\mathrm{ACD}\right)$ and subsequent near visual acuity. Different
\end{abstract}

Correspondence to: Dr Ján Lešták or Mrs. Markéta Žáková, CTU in Prague, Faculty of Biomedical Engineering, Sítná sq. 3105, 27201 Kladno 2, Czech Republic

E-mail: lestak@seznam.cz

E-mail: marketa.zakova@fbmi.cvut.cz

Abbreviations: ACD, anterior chamber depth; AL, axial length of the eye; IOL, intraocular lens; $\mathrm{K}_{\mathrm{C}}$, postoperative keratometry value-centre of the cornea; $\mathrm{K}_{\mathrm{VA}}$, postoperative keratometry value-visual axis of the cornea; UDVA, decimal value of uncorrected distance visual acuity; $\mathrm{UNVA}_{\mathrm{H}}$, decimal value of uncorrected near visual acuity in horizontal position; $\mathrm{UNVA}_{\mathrm{V}}$, decimal value of uncorrected near visual acuity in vertical position

Key words: near visual acuity, cataract surgery, post-cataract refraction, reading plane, monofocal intraocular lenses dependence was found after categorising the group according to the axial length of the eye. In conclusion, the near visual acuity in eyes with an implanted monofocal lens for emmetropy to distance reached higher values at the vertical vs. horizontal position of the eyes. However, neither of the observed parameters $\left(\mathrm{K}_{\mathrm{C}}, \mathrm{K}_{\mathrm{VA}}\right.$ or $\left.\mathrm{ACD}\right)$ can be unambiguously determined as decisive for the assumption of the described feature.

\section{Introduction}

In the framework of cataract surgery, a comfortable postoperative uncorrected distance visual acuity (UDVA) may be successfully achieved due to the development of modern biometric methods and calculation formulas. However, patients also require to be able to see a normal reading text without further correction, which has led to the development of multifocal or accommodation intraocular lenses (IOLs). The challenge of these models is the number of contraindications, risk of asthenopic problems caused by higher-order aberrations, as well as the additional required payment by the patient.

For pseudophakic eyes, in addition to the optimal UDVA, the optimal uncorrected near visual acuity (UNVA) may also be seen, although a monofocal IOL has been implanted. In a previous study (1) it was proven that optimal near visual acuity may be achieved even without targeted postoperative myopisation in eyes with a short axial length (AL). For $30.33 \%$ of eyes with a UNVA of $\geq 0.6$, the AL was $\leq 23.5 \mathrm{~mm}$, whereas even for a UNVA of 0.8 , the AL was up to $22.5 \mathrm{~mm}$. Theoretically, a significant role of the postoperative pseudo-accommodation amplitude in such eyes may be expected, particularly the effect of an axial shift of the IOL causing a reduction of the anterior chamber depth (ACD), which occurs even when the direction of view of the eye is changed. It was proven that a change in the position of the eye affects the ACD, albeit to a lesser extent than predicted (2). The hydrodynamic status in the eye is practically indefinable with regard to several influencing factors. However, the validity of Pascal's law is hypothesised, and due to the hydrostatic pressure under the influence of a small gravitational force, the shift of the IOL causes a slight myopisation that likely confers an increase in near visual acuity.

The subject of the present study was a statistical evaluation of a change in the UNVA depending on the position of the text or a change of the direction of the eye, including an analysis of a mutual correlation of the individual eye parameters. 
Table I. Input values and parameters of the study.

\begin{tabular}{|c|c|c|c|c|c|c|c|c|}
\hline Eye no. & $\mathrm{AL}(\mathrm{mm})$ & IOL & UDVA & $\mathrm{ACD}(\mathrm{mm})$ & $\mathrm{K}_{\mathrm{C}}(\mathrm{D})$ & $\mathrm{K}_{\mathrm{VA}}(\mathrm{D})$ & $\mathrm{UNVA}_{\mathrm{H}}$ & $\mathrm{UNVA}_{\mathrm{V}}$ \\
\hline 1 & 21.16 & $27.5 \mathrm{SA}$ & 0.80 & 3.90 & 44.68 & 44.95 & 0.40 & 0.50 \\
\hline 2 & 21.28 & $26.5 \mathrm{SA}$ & 1.00 & 3.90 & 43.77 & 42.65 & 0.80 & 0.80 \\
\hline 3 & 21.28 & $27.0 \mathrm{SA}$ & 1.00 & 4.00 & 46.05 & 45.33 & 0.50 & 0.60 \\
\hline 4 & 21.43 & $23.0 \mathrm{SA}$ & 1.20 & 4.10 & 46.50 & 46.71 & 0.60 & 0.60 \\
\hline 5 & 21.46 & $30.5 \mathrm{SA}$ & 1.00 & 3.40 & 42.15 & 41.68 & 0.80 & 0.80 \\
\hline 6 & 21.47 & $23.0 \mathrm{SA}$ & 1.20 & 4.10 & 46.50 & 46.74 & 0.60 & 0.60 \\
\hline 7 & 21.54 & $25.5 \mathrm{SA}$ & 1.20 & 3.80 & 44.86 & 45.46 & 1.00 & 1.00 \\
\hline 8 & 21.64 & $24.5 \mathrm{SA}$ & 1.20 & 3.80 & 46.10 & 45.77 & 0.80 & 0.80 \\
\hline 9 & 21.68 & $24.0 \mathrm{SA}$ & 1.20 & 3.80 & 46.10 & 45.84 & 0.80 & 0.80 \\
\hline 10 & 21.75 & $26.0 \mathrm{SA}$ & 1.00 & 3.80 & 43.12 & 44.14 & 0.40 & 0.60 \\
\hline 11 & 21.75 & $25.5 \mathrm{SA}$ & 1.00 & 3.80 & 42.00 & 43.00 & 0.40 & 0.60 \\
\hline 12 & 21.80 & $24.5 \mathrm{SA}$ & 1.00 & 4.19 & 45.57 & 45.45 & 0.80 & 0.80 \\
\hline 13 & 21.80 & $25.0 \mathrm{SA}$ & 1.00 & 4.19 & 44.67 & 45.06 & 0.80 & 0.80 \\
\hline 14 & 21.80 & $27.0 \mathrm{SA}$ & 1.20 & 3.80 & 47.16 & 45.55 & 1.00 & 1.00 \\
\hline 15 & 21.87 & $24.0 \mathrm{SA}$ & 1.20 & 3.50 & 45.20 & 45.67 & 0.50 & 0.50 \\
\hline 16 & 21.87 & $24.5 \mathrm{SA}$ & 1.00 & 3.70 & 44.78 & 44.45 & 0.50 & 0.60 \\
\hline 17 & 21.94 & $24.5 \mathrm{MA}$ & 1.00 & 3.30 & 45.91 & 44.76 & 0.30 & 0.40 \\
\hline 18 & 21.95 & $24.0 \mathrm{SA}$ & 1.50 & 3.80 & 45.81 & 45.19 & 0.20 & 0.30 \\
\hline 19 & 21.95 & $24.5 \mathrm{SA}$ & 1.00 & 3.50 & 45.00 & 44.81 & 0.40 & 0.40 \\
\hline 20 & 21.96 & $24.0 \mathrm{SA}$ & 1.20 & 3.50 & 45.58 & 45.54 & 0.50 & 0.50 \\
\hline 21 & 21.96 & $23.5 \mathrm{SA}$ & 1.50 & 3.90 & 45.64 & 45.93 & 0.20 & 0.30 \\
\hline 22 & 21.99 & $25.0 \mathrm{SA}$ & 1.00 & 3.50 & 45.07 & 44.36 & 0.40 & 0.40 \\
\hline 23 & 21.99 & $24.5 \mathrm{MA}$ & 1.00 & 3.50 & 45.70 & 44.47 & 0.30 & 0.40 \\
\hline 24 & 22.12 & $26.5 \mathrm{SA}$ & 1.00 & 4.00 & 46.06 & 45.54 & 0.50 & 0.60 \\
\hline 25 & 22.13 & $24.5 \mathrm{SA}$ & 1.00 & 3.50 & 44.84 & 44.53 & 0.50 & 0.60 \\
\hline 26 & 22.14 & $22.0 \mathrm{SA}$ & 1.20 & 3.60 & 46.35 & 45.79 & 0.40 & 0.40 \\
\hline 27 & 22.16 & $24.0 \mathrm{IQ}$ & 1.00 & 2.00 & 45.64 & 45.66 & 0.60 & 0.60 \\
\hline 28 & 22.20 & $22.5 \mathrm{SA}$ & 1.20 & 3.80 & 45.93 & 46.25 & 0.50 & 0.60 \\
\hline 29 & 22.22 & $25.0 \mathrm{IQ}$ & 1.20 & 4.20 & 44.00 & 44.01 & 0.30 & 0.30 \\
\hline 30 & 22.28 & $22.0 \mathrm{SA}$ & 1.20 & 3.80 & 46.26 & 46.48 & 0.50 & 0.60 \\
\hline 31 & 22.32 & $23.5 \mathrm{IQ}$ & 1.00 & 2.00 & 45.61 & 44.80 & 0.50 & 0.60 \\
\hline 32 & 22.35 & $22.0 \mathrm{SA}$ & 1.00 & 3.60 & 45.94 & 46.52 & 0.60 & 0.60 \\
\hline 33 & 22.38 & $24.5 \mathrm{SA}$ & 1.00 & 3.70 & 43.94 & 43.30 & 0.50 & 0.50 \\
\hline 34 & 22.40 & $22.0 \mathrm{SA}$ & 1.00 & 3.70 & 45.28 & 45.11 & 0.60 & 0.60 \\
\hline 35 & 22.42 & $24.5 \mathrm{IQ}$ & 1.20 & 3.60 & 44.27 & 44.38 & 0.30 & 0.30 \\
\hline 36 & 22.46 & $24.0 \mathrm{SA}$ & 1.00 & 3.70 & 42.72 & 42.65 & 0.50 & 0.50 \\
\hline 37 & 22.47 & $23.0 \mathrm{SA}$ & 1.20 & 4.20 & 44.45 & 44.80 & 0.30 & 0.40 \\
\hline
\end{tabular}

B, AL 22.5-23.5 mm

\begin{tabular}{|c|c|c|c|c|c|c|c|c|}
\hline Eye no. & $\mathrm{AL}(\mathrm{mm})$ & $\mathrm{IOL}$ & UDVA & $\mathrm{ACD}(\mathrm{mm})$ & $\mathrm{K}_{\mathrm{C}}(\mathrm{D})$ & $\mathrm{K}_{\mathrm{VA}}(\mathrm{D})$ & $\mathrm{UNVA}_{\mathrm{H}}$ & $\mathrm{UNVA}_{\mathrm{V}}$ \\
\hline 38 & 22.51 & $23.0 \mathrm{SA}$ & 1.20 & 4.30 & 44.46 & 44.42 & 0.30 & 0.40 \\
\hline 39 & 22.56 & $23.0 \mathrm{SN}$ & 1.00 & 3.27 & 42.50 & 45.34 & 0.50 & 0.50 \\
\hline 40 & 22.58 & $23.0 \mathrm{SA}$ & 1.20 & 3.70 & 46.47 & 44.55 & 0.40 & 0.40 \\
\hline 41 & 22.58 & $23.0 \mathrm{SA}$ & 1.00 & 3.40 & 47.90 & 47.48 & 0.80 & 0.80 \\
\hline 42 & 22.64 & $23.0 \mathrm{SA}$ & 1.00 & 3.97 & 43.62 & 43.96 & 0.40 & 0.50 \\
\hline 43 & 22.66 & $23.0 \mathrm{SA}$ & 1.00 & 3.80 & 46.48 & 44.41 & 0.80 & 0.80 \\
\hline 44 & 22.70 & $22.0 \mathrm{SA}$ & 1.20 & 3.70 & 46.50 & 45.44 & 0.80 & 0.80 \\
\hline 45 & 22.73 & $21.0 \mathrm{SA}$ & 1.00 & 4.20 & 46.56 & 46.78 & 0.60 & 0.80 \\
\hline
\end{tabular}


Table I. Continued.

\begin{tabular}{|c|c|c|c|c|c|c|c|c|}
\hline \multicolumn{9}{|c|}{$\mathrm{B}, \mathrm{AL} 22.5-23.5 \mathrm{~mm}$} \\
\hline Eye no. & $\mathrm{AL}(\mathrm{mm})$ & IOL & UDVA & $\mathrm{ACD}(\mathrm{mm})$ & $\mathrm{K}_{\mathrm{C}}(\mathrm{D})$ & $\mathrm{K}_{\mathrm{VA}}(\mathrm{D})$ & $\mathrm{UNVA}_{\mathrm{H}}$ & $\mathrm{UNVA}_{\mathrm{V}}$ \\
\hline 46 & 22.74 & $26.5 \mathrm{IQ}$ & 1.20 & 3.80 & 41.24 & 40.46 & 0.40 & 0.50 \\
\hline 47 & 22.80 & $22.0 \mathrm{SN}$ & 1.20 & 3.28 & 44.50 & 44.24 & 0.50 & 0.50 \\
\hline 48 & 22.80 & $21.5 \mathrm{SA}$ & 1.20 & 3.80 & 45.14 & 46.19 & 0.80 & 0.80 \\
\hline 49 & 22.81 & $22.5 \mathrm{SA}$ & 1.50 & 3.96 & 45.15 & 45.16 & 0.60 & 0.60 \\
\hline 50 & 22.81 & $22.0 \mathrm{SA}$ & 1.50 & 3.80 & 44.36 & 44.44 & 0.60 & 0.60 \\
\hline 51 & 22.81 & $21.5 \mathrm{SA}$ & 1.50 & 3.90 & 43.93 & 43.74 & 0.50 & 0.60 \\
\hline 52 & 22.85 & $22.0 \mathrm{SA}$ & 1.00 & 3.90 & 42.15 & 41.15 & 0.40 & 0.50 \\
\hline 53 & 22.87 & $20.0 \mathrm{SA}$ & 1.00 & 4.20 & 47.18 & 46.32 & 0.60 & 0.80 \\
\hline 54 & 22.87 & $22.0 \mathrm{SA}$ & 1.20 & 4.30 & 42.81 & 42.44 & 0.50 & 0.60 \\
\hline 55 & 22.92 & $21.5 \mathrm{IQ}$ & 1.50 & 4.00 & 45.12 & 44.66 & 0.60 & 0.60 \\
\hline 56 & 22.94 & $22.0 \mathrm{MA}$ & 0.80 & 3.60 & 44.10 & 45.59 & 0.40 & 0.50 \\
\hline 57 & 22.95 & $22.0 \mathrm{MA}$ & 0.80 & 3.70 & 45.60 & 45.69 & 0.40 & 0.50 \\
\hline 58 & 22.96 & $22.0 \mathrm{SA}$ & 1.00 & 2.20 & 43.73 & 43.50 & 0.50 & 0.50 \\
\hline 59 & 22.96 & $22.5 \mathrm{SA}$ & 1.00 & 3.80 & 45.19 & 43.50 & 0.50 & 0.60 \\
\hline 60 & 22.98 & $22.0 \mathrm{SA}$ & 1.00 & 3.80 & 42.37 & 43.06 & 0.50 & 0.60 \\
\hline 61 & 22.99 & $22.0 \mathrm{SA}$ & 1.00 & 4.00 & 45.96 & 45.71 & 0.50 & 0.50 \\
\hline 62 & 23.00 & $21.5 \mathrm{SA}$ & 1.00 & 3.60 & 43.93 & 44.73 & 0.60 & 0.60 \\
\hline 63 & 23.10 & $20.5 \mathrm{SA}$ & 1.00 & 3.80 & 44.65 & 44.57 & 0.50 & 0.50 \\
\hline 64 & 23.10 & $22.5 \mathrm{MA}$ & 1.50 & 4.10 & 42.48 & 43.13 & 0.40 & 0.50 \\
\hline 65 & 23.12 & $24.0 \mathrm{SA}$ & 1.50 & 4.10 & 40.82 & 40.93 & 0.60 & 0.60 \\
\hline 66 & 23.17 & $21.5 \mathrm{SA}$ & 1.00 & 4.20 & 42.78 & 41.76 & 0.50 & 0.50 \\
\hline 67 & 23.24 & $24.5 \mathrm{IQ}$ & 1.20 & 3.80 & 40.20 & 41.07 & 0.40 & 0.40 \\
\hline 68 & 23.26 & $21.0 \mathrm{MA}$ & 1.00 & 4.20 & 45.66 & 44.75 & 0.60 & 0.60 \\
\hline 69 & 23.29 & $21.0 \mathrm{MA}$ & 1.00 & 4.20 & 44.32 & 45.19 & 0.60 & 0.60 \\
\hline 70 & 23.30 & $23.0 \mathrm{IQ}$ & 1.20 & 3.60 & 42.09 & 42.12 & 0.50 & 0.60 \\
\hline 71 & 23.31 & $21.0 \mathrm{SA}$ & 1.50 & 3.80 & 43.90 & 43.45 & 0.50 & 0.60 \\
\hline 72 & 23.32 & $23.0 \mathrm{IQ}$ & 1.00 & 3.60 & 43.09 & 43.29 & 0.50 & 0.60 \\
\hline 73 & 23.35 & $20.0 \mathrm{MA}$ & 1.20 & 3.60 & 45.36 & 45.26 & 0.60 & 0.60 \\
\hline 74 & 23.37 & $20.5 \mathrm{SA}$ & 1.20 & 3.70 & 43.54 & 44.35 & 0.50 & 0.50 \\
\hline 75 & 23.40 & $21.5 \mathrm{SA}$ & 1.00 & 3.60 & 44.26 & 44.94 & 0.60 & 0.60 \\
\hline 76 & 23.40 & $24.5 \mathrm{SA}$ & 1.50 & 4.10 & 41.62 & 42.64 & 0.60 & 0.60 \\
\hline 77 & 23.40 & $23.0 \mathrm{SA}$ & 1.20 & 4.20 & 41.88 & 42.71 & 0.40 & 0.50 \\
\hline 78 & 23.41 & $20.0 \mathrm{MA}$ & 1.20 & 3.90 & 44.45 & 45.69 & 0.50 & 0.60 \\
\hline 79 & 23.41 & $20.5 \mathrm{MA}$ & 1.20 & 3.80 & 44.79 & 45.02 & 0.50 & 0.50 \\
\hline 80 & 23.41 & $21.5 \mathrm{MA}$ & 1.20 & 3.90 & 43.94 & 41.59 & 0.50 & 0.50 \\
\hline 81 & 23.42 & $21.5 \mathrm{MA}$ & 1.20 & 3.80 & 42.43 & 43.26 & 0.60 & 0.80 \\
\hline 82 & 23.42 & $22.0 \mathrm{MA}$ & 1.20 & 3.90 & 42.29 & 43.29 & 0.40 & 0.40 \\
\hline 83 & 23.44 & $20.5 \mathrm{SA}$ & 1.20 & 3.90 & 44.15 & 44.36 & 0.50 & 0.50 \\
\hline 84 & 23.44 & $21.0 \mathrm{MA}$ & 1.20 & 3.80 & 43.44 & 43.37 & 0.50 & 0.50 \\
\hline 85 & 23.48 & $20.5 \mathrm{SN}$ & 1.20 & 4.30 & 43.22 & 44.76 & 0.50 & 0.50 \\
\hline 86 & 23.50 & $20.0 \mathrm{SN}$ & 1.20 & 4.40 & 44.90 & 45.30 & 0.50 & 0.50 \\
\hline 87 & 23.50 & $21.5 \mathrm{MA}$ & 1.20 & 3.60 & 45.65 & 44.57 & 0.60 & 0.60 \\
\hline 88 & 23.50 & $20.0 \mathrm{SA}$ & 1.20 & 4.00 & 43.62 & 43.51 & 0.30 & 0.30 \\
\hline 89 & 23.50 & $20.0 \mathrm{SA}$ & 1.50 & 3.70 & 43.83 & 45.61 & 0.20 & 0.30 \\
\hline
\end{tabular}

$\mathrm{C}, \mathrm{AL}>23.5 \mathrm{~mm}$

\begin{tabular}{lcccccccc}
\hline Eye no. & AL $(\mathrm{mm})$ & IOL & UDVA & ACD $(\mathrm{mm})$ & $\mathrm{K}_{\mathrm{C}}(\mathrm{D})$ & $\mathrm{K}_{\mathrm{VA}}(\mathrm{D})$ & $\mathrm{UNVA}_{\mathrm{H}}$ & $\mathrm{UNVA}_{\mathrm{V}}$ \\
\hline 90 & 23.51 & $21.5 \mathrm{MA}$ & 1.20 & 3.80 & 41.93 & 42.99 & 0.40 & 0.40
\end{tabular}


Table I. Continued.

$\mathrm{C}, \mathrm{AL}>23.5 \mathrm{~mm}$

\begin{tabular}{|c|c|c|c|c|c|c|c|c|}
\hline Eye no. & $\mathrm{AL}(\mathrm{mm})$ & IOL & UDVA & $\mathrm{ACD}(\mathrm{mm})$ & $\mathrm{K}_{\mathrm{C}}(\mathrm{D})$ & $\mathrm{K}_{\mathrm{VA}}(\mathrm{D})$ & $\mathrm{UNVA}_{\mathrm{H}}$ & $\mathrm{UNVA}_{\mathrm{V}}$ \\
\hline 91 & 23.53 & 19.5 IQ & 1.00 & 3.70 & 44.56 & 44.47 & 0.50 & 0.50 \\
\hline 92 & 23.54 & $23.5 \mathrm{SA}$ & 1.20 & 3.70 & 40.92 & 41.41 & 0.60 & 0.80 \\
\hline 93 & 23.55 & $21.5 \mathrm{SA}$ & 1.00 & 4.20 & 43.05 & 43.81 & 0.60 & 0.60 \\
\hline 94 & 23.57 & $20.0 \mathrm{MA}$ & 1.20 & 3.90 & 44.22 & 44.57 & 0.50 & 0.50 \\
\hline 95 & 23.58 & $20.5 \mathrm{SN}$ & 1.00 & 3.96 & 46.21 & 44.91 & 0.50 & 0.50 \\
\hline 96 & 23.60 & 21.5 IQ & 1.50 & 4.10 & 45.90 & 45.86 & 0.60 & 0.60 \\
\hline 97 & 23.61 & $19.5 \mathrm{MA}$ & 1.00 & 4.10 & 45.13 & 45.66 & 0.20 & 0.30 \\
\hline 98 & 23.63 & 18.5 IQ & 1.00 & 3.80 & 45.43 & 45.99 & 0.50 & 0.50 \\
\hline 99 & 23.66 & $20.0 \mathrm{MA}$ & 1.00 & 4.20 & 45.81 & 46.16 & 0.20 & 0.30 \\
\hline 100 & 23.67 & $19.5 \mathrm{SN}$ & 1.00 & 4.00 & 43.54 & 44.85 & 0.50 & 0.50 \\
\hline 101 & 23.69 & $18.5 \mathrm{MA}$ & 1.20 & 4.20 & 45.96 & 44.33 & 0.50 & 0.60 \\
\hline 102 & 23.73 & $22.5 \mathrm{SA}$ & 1.20 & 3.80 & 42.53 & 42.05 & 0.60 & 0.80 \\
\hline 103 & 23.74 & $21.0 \mathrm{MA}$ & 1.20 & 4.10 & 43.57 & 42.96 & 0.30 & 0.30 \\
\hline 104 & 23.78 & $21.0 \mathrm{SA}$ & 1.00 & 4.20 & 41.24 & 44.98 & 0.50 & 0.60 \\
\hline 105 & 23.81 & $20.5 \mathrm{MA}$ & 1.20 & 4.10 & 42.83 & 44.14 & 0.30 & 0.30 \\
\hline 106 & 23.85 & $20.5 \mathrm{MA}$ & 1.20 & 3.80 & 43.19 & 43.56 & 0.60 & 0.80 \\
\hline 107 & 23.88 & $22.5 \mathrm{SA}$ & 1.20 & 4.20 & 41.28 & 41.42 & 0.50 & 0.50 \\
\hline 108 & 23.90 & $20.0 \mathrm{SA}$ & 1.00 & 3.90 & 46.56 & 45.50 & 0.50 & 0.60 \\
\hline 109 & 23.90 & $20.0 \mathrm{SA}$ & 1.00 & 3.90 & 45.81 & 43.06 & 0.50 & 0.60 \\
\hline 110 & 23.92 & $22.5 \mathrm{SA}$ & 1.20 & 4.10 & 41.04 & 41.07 & 0.50 & 0.50 \\
\hline 111 & 23.97 & $22.0 \mathrm{SA}$ & 1.00 & 4.00 & 40.43 & 40.80 & 0.50 & 0.50 \\
\hline 112 & 24.12 & $21.5 \mathrm{IQ}$ & 1.20 & 3.90 & 41.40 & 41.60 & 0.20 & 0.30 \\
\hline 113 & 24.13 & $21.5 \mathrm{IQ}$ & 1.20 & 3.80 & 41.50 & 41.97 & 0.20 & 0.30 \\
\hline 114 & 24.27 & $21.5 \mathrm{SA}$ & 1.00 & 3.90 & 40.68 & 41.15 & 0.50 & 0.50 \\
\hline 115 & 24.35 & $17.5 \mathrm{MA}$ & 1.00 & 3.90 & 44.72 & 44.94 & 0.50 & 0.60 \\
\hline 116 & 24.46 & $17.0 \mathrm{MA}$ & 1.50 & 3.90 & 44.84 & 44.91 & 0.60 & 0.80 \\
\hline 117 & 24.65 & $22.0 \mathrm{MA}$ & 1.00 & 4.10 & 41.66 & 41.68 & 0.50 & 0.50 \\
\hline 118 & 24.75 & 18.5 IQ & 1.50 & 4.20 & 42.74 & 42.50 & 0.50 & 0.50 \\
\hline 119 & 24.76 & $18.5 \mathrm{IQ}$ & 1.50 & 4.40 & 42.85 & 42.80 & 0.50 & 0.50 \\
\hline 120 & 24.81 & $15.5 \mathrm{MA}$ & 1.20 & 4.00 & 44.71 & 45.81 & 0.60 & 0.60 \\
\hline 121 & 24.83 & $22.0 \mathrm{MA}$ & 1.00 & 4.10 & 41.26 & 41.15 & 0.50 & 0.50 \\
\hline
\end{tabular}

AL, axial length of eye; IOL, intraocular lens-power and model (SA=SA60AT, MA=MA50BM, IQ=SN60WF IQ); UDVA, decimal value of uncorrected distance visual acuity; $\mathrm{ACD}$, anterior chamber depth; $\mathrm{K}_{\mathrm{C}}$ postoperative keratometry value-centre of the cornea; $\mathrm{K}_{\mathrm{VA}}$, postoperative keratometry value-visual axis of the cornea; $\mathrm{UNVA}_{\mathrm{H}}$, decimal value of uncorrected near visual acuity in the horizontal position; UNVA, decimal value of uncorrected near visual acuity in the vertical position.

\section{Materials and methods}

Study parameters. In total, 121 eyes were evaluated following surgery in 65 patients. Patients who underwent cataract surgery with implantation of a monofocal IOL were included in the study. The patient selection was performed randomly, depending on the time the patients came for the check-up examinations between January and March 2017. The surgery was performed by a single surgeon using an identical technique (phacoemulsification using the initial incision of $2.2 \mathrm{~mm}$ ), and the relation SRK/T was used to calculate the optical power of the IOL for emmetropy; the evaluation period was at least 1 month post-surgery. The following models of IOL were implanted: MA50BM $(58.68 \%$

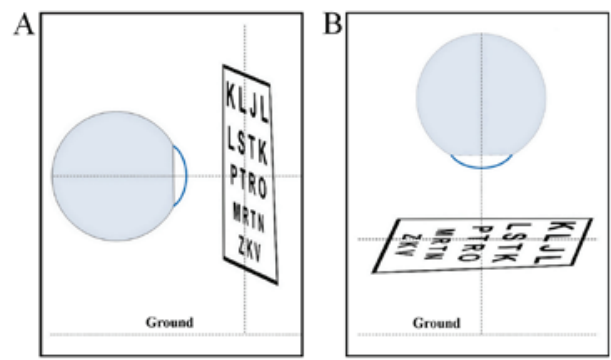

Figure 1. Demonstration of the position of the mutual axes. (A) The viewing axis of the eye is parallel with the ground-UNVA $\mathrm{H}_{\mathrm{H}}$; $\left.\mathrm{B}\right)$ the viewing axis of the eye is pointing towards the ground-UNVA $\mathrm{UNVA}_{\mathrm{H}}$, decimal value of uncorrected near visual acuity in the horizontal position; $\mathrm{UNVA}_{\mathrm{V}}$, decimal value of uncorrected near visual acuity in the vertical position. 
Table II. Mean parameters of the input group following categorization into the groups.

\begin{tabular}{|c|c|c|c|c|}
\hline \multirow[b]{2}{*}{ Parameters } & \multirow[b]{2}{*}{ Values of the whole group } & \multicolumn{3}{|c|}{ Values based on the AL groups } \\
\hline & & $<22.5$ & $\leq 22.5-23.5 \geq$ & $>23.5$ \\
\hline Count (eyes) & 121 & 37 & 52 & 32 \\
\hline $\mathrm{AL}(\mathrm{mm})$ & $22.96 \pm 0.85$ & $21.93 \pm 0.36$ & $23.09 \pm 0.31$ & $23.96 \pm 0.43$ \\
\hline $\mathrm{ACD}(\mathrm{mm})$ & $3.83 \pm 0.37$ & $3.68 \pm 0.47$ & $3.84 \pm 0.35$ & $3.68 \pm 0.47$ \\
\hline $\mathrm{K}_{\mathrm{C}}(\mathrm{D})$ & $44.19 \pm 1.73$ & $45.11 \pm 1.21$ & $44.04 \pm 1.65$ & $43.36 \pm 1.91$ \\
\hline $\mathrm{K}_{\mathrm{VA}}(\mathrm{D})$ & $44.21 \pm 1.58$ & $44.96 \pm 1.17$ & $44.10 \pm 1.55$ & $43.53 \pm 1.73$ \\
\hline
\end{tabular}

Values are presented as mean \pm standard deviation. $\mathrm{AL}$, axial length of eye; $\mathrm{ACD}$, anterior chamber depth; $\mathrm{K}_{\mathrm{C}}$, postoperative keratometry value-centre of the cornea; $\mathrm{K}_{\mathrm{VA}}$, postoperative keratometry value-visual axis of the cornea.

Table III. Mean values of $\mathrm{UNVA}_{\mathrm{H}}$ and $\mathrm{UNVA}_{\mathrm{V}}$.

\begin{tabular}{|c|c|c|c|c|}
\hline Category & Mean (mm) & $\mathrm{SD}$ & $\mathrm{t}$ & P-value \\
\hline \multicolumn{5}{|l|}{ All AL } \\
\hline $\mathrm{UNVA}_{\mathrm{H}}$ & 0.51 & 0.15 & -8.18 & $<0.001$ \\
\hline $\mathrm{UNVA}_{\mathrm{V}}$ & 0.56 & 0.15 & & \\
\hline \multicolumn{5}{|l|}{$\mathrm{AL}_{<22.5}$} \\
\hline $\mathrm{UNVA}_{\mathrm{H}}$ & 0.53 & 0.20 & -4.62 & $<0.001$ \\
\hline $\mathrm{UNVA}_{\mathrm{V}}$ & 0.58 & 0.18 & & \\
\hline \multicolumn{5}{|l|}{$\mathrm{AL}_{22.5-23.5}$} \\
\hline $\mathrm{UNVA}_{\mathrm{H}}$ & 0.52 & 0.12 & -5.25 & $<0.001$ \\
\hline $\mathrm{UNVA}_{\mathrm{V}}$ & 0.56 & 0.12 & & \\
\hline \multicolumn{5}{|l|}{$\mathrm{AL}_{>23.5}$} \\
\hline $\mathrm{UNVA}_{\mathrm{H}}$ & 0.47 & 0.13 & -4.19 & $<0.001$ \\
\hline $\mathrm{UNVA}_{\mathrm{V}}$ & 0.52 & 0.16 & & \\
\hline
\end{tabular}

AL, axial length of eye (different groups); $\mathrm{UNVA}_{\mathrm{H}}$, decimal value of uncorrected near visual acuity in the horizontal position; $\mathrm{UNVA}_{\mathrm{V}}$, decimal value of uncorrected near visual acuity in the vertical position; SD, standard deviation.

of eyes), SA60AT (23.14\%), SN60WF (13.22\%) and SN6ATx $(4.96 \%)$. Only the postoperatively emmetropic eyes among the eyes examined were included, with $97.52 \%$ of the eyes achieving a vision of 1.0 or better (the remaining $2.48 \%$ of the eyes achieved a vision of 0.8 , whereas no correction improved the vision). Input data for the study are summarised in Table I.

The evaluated postoperative parameters included the typography values (Anterior Segment Analyser Orbscan II) for optical power in the central part of the cornea $(\mathrm{KC})$, as well as in the visual axis (KVA), anterior chamber depth (ACD; OcuScan biometer) and eye axial length (AL; OcuScan biometer).

To determine the near vision values, each eye was examined separately using the Jäeger table ZEISS at a distance of $40 \mathrm{~cm}$ and its perpendicular position relative to the eye viewing axis. First, the value of the least read text was recorded at the

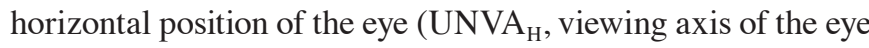
parallel with the floor) and subsequently at the vertical position (UNVA ${ }_{V}$, viewing axis of the eye perpendicular to the floor). Demonstration of the position of the mutual axes is shown on
Table IV. Correlation coefficients for the whole group and different ALs.

\begin{tabular}{lllll}
\hline & \multicolumn{4}{c}{ Variables } \\
\cline { 2 - 5 } AL $(\mathrm{mm})$ & $\mathrm{ACD}$ & $\mathrm{K}_{\mathrm{C}}$ & $\mathrm{K}_{\mathrm{VA}}$ & $\mathrm{AL}$ \\
\hline Whole group & & & & \\
$\mathrm{UNVA}_{\mathrm{H}}$ & -0.06 & 0.24 & 0.18 & -0.21 \\
$\mathrm{UNVA}_{\mathrm{V}}$ & -0.04 & 0.22 & 0.17 & -0.22 \\
$<22.5$ & & & & \\
$\mathrm{UNVA}_{\mathrm{H}}$ & 0.06 & 0.11 & 0.06 & -0.39 \\
UNVA $_{\mathrm{V}}$ & 0.07 & 0.06 & 0.04 & -0.45 \\
$22.5-23.5$ & & & & \\
$\mathrm{UNVA}_{\mathrm{H}}$ & -0.09 & 0.45 & 0.34 & -0.21 \\
UNVA $_{\mathrm{V}}$ & 0.01 & 0.42 & 0.33 & -0.29 \\
$>23.5$ & & & & \\
UNVA $_{\mathrm{H}}$ & -0.11 & 0.03 & -0.01 & 0.12 \\
UNVA $_{\mathrm{V}}$ & -0.28 & 0.07 & 0.02 & 0.05 \\
\hline
\end{tabular}

$\mathrm{AL}$, axial length of eye; $\mathrm{ACD}$, anterior chamber depth; $\mathrm{K}_{\mathrm{C}}$, postoperative keratometry value-centre of the cornea; $\mathrm{K}_{\mathrm{VA}}$, postoperative keratometry value-visual axis of the cornea; $\mathrm{UNVA}_{\mathrm{H}}$, decimal value of uncorrected near visual acuity in the horizontal position; $\mathrm{UNVA}_{\mathrm{V}}$, decimal value of uncorrected near visual acuity in the vertical position.

Fig. 1. The observed parameters were evaluated for the whole group of patients, but also following categorisation of the group into three cohorts according to the AL: The group of short eyes $\left(\mathrm{AL}_{<22.5}\right)$ included eyes up to $22.5 \mathrm{~mm}$, AL 22.5-23.5 mm was identified as the group of normal eyes $\left(\mathrm{AL}_{22.5-23.5}\right)$ and the cohort of long eyes had an $\mathrm{AL}>23.5 \mathrm{~mm}\left(\mathrm{AL}_{>23.5}\right)$.

\section{Results}

Mean parameters of the input group following categorization. The mean age of the group was 71 years. The mean parameter values of the eyes included in the study are presented in Table II.

Mean values of $U N V A_{H}$ and $U N V A_{V}$. The paired t-test was used to compare visual acuity at the horizontal and vertical 
position of the eye for the whole group of patients. The results revealed that, in the case of $\mathrm{UNVA}_{\mathrm{H}}$ for the horizontal position of the eye, the values were lower compared with $\mathrm{UNVA}_{\mathrm{V}}$ for the vertical position of the eye (mean 0.51 vs. 0.56 , respectively; $\mathrm{P}<0.001$ ). A higher or identical $\mathrm{UNVA}_{\mathrm{V}}$ value compared with $\mathrm{UNVA}_{\mathrm{H}}$ was always achieved in all groups based on the AL. Visual improvement in $\mathrm{UNVA}_{\mathrm{V}}$ was observed in $40.2 \%$ of the eyes. The lowest mean value for the $\mathrm{UNVA}_{\mathrm{H}}$ was recorded in eyes with an $\mathrm{AL}>23.5 \mathrm{~mm}$. The highest mean value for the $\mathrm{UNVA}_{\mathrm{V}}$ was achieved in short eyes (mean 0.58; $\mathrm{P}<0.001$ ). The complete values are summarised in Table III.

Correlation coefficients. Evaluation of the association of the eye parameters for $\mathrm{UNVA}_{\mathrm{H}}$ and $\mathrm{UNVA}_{\mathrm{H}}$ was performed using correlation coefficients (Table IV). We did not identify a more significant than weak correlation value for the whole group. For the $\mathrm{AL}_{<22.5}$ group, we observed a weak negative correlation of the $\mathrm{UNVA}_{\mathrm{H}}$ with AL (-0.39), but a moderate negative correlation was observed for AL and $\mathrm{UNVA}_{\mathrm{V}}(-0.45)$. In the $\mathrm{AL}_{22.5-23.5}$ group of eyes, the positive correlation of the $\mathrm{UNVA}_{\mathrm{H}}$ with $\mathrm{K}_{\mathrm{C}}(0.45)$ and $\mathrm{K}_{\mathrm{VA}}(0.34)$, and of $\mathrm{UNVA}_{\mathrm{V}}$ with $\mathrm{K}_{\mathrm{C}}(0.42)$ and $\mathrm{K}_{\mathrm{VA}}(0.33)$, was found to be more significant. For eyes with an $\mathrm{AL}>23.5 \mathrm{~mm}$ there was only a weak negative correlation of $\mathrm{UNVA}_{\mathrm{V}}$ with ACD (-0.28).

\section{Discussion}

During the postoperative evaluation of patients with implanted monofocal IOL following standard cataract surgery, an unexpectedly high postoperative near visual acuity was observed. To predict this effect, scientific studies have gradually attempted to identify a correlation between eye parameters and this phenomenon. The pupil size and AL were not conclusively found to be correlated with near vision in 84 patients. However, a pupil diameter $<2.6 \mathrm{~mm}$ along with $\mathrm{AL}<23 \mathrm{~mm}$ demonstrated better near visual acuity (3). Our previous study partially supports these conclusions, as our data revealed a moderate negative correlation of the postoperative UNVA with a decreasing AL ( $<22.5 \mathrm{~mm})(1)$.

Association of age with UNVA was not proven in the present study, whereas Hayashi et al (4) confirmed that patient age is a negative factor affecting the postoperative amplitude of pseudo-accommodation (correlation coefficient of -0.49); however, that study also included patients aged $<40$ years, while only 3 patients were $<60$ years of age in the present study. A relevant assessment of the dependence on age would require a higher age range. According to Nanavaty et al (5), corneal astigmatism (against the rule) is a significant factor that increases the possibility of pseudo-accommodation up to 10-fold.

A more statistically significant dependence on preoperative $\mathrm{ACD}, \mathrm{K}_{\mathrm{C}}$ or $\mathrm{K}_{\mathrm{VA}}$ for the whole group of patients was not observed. When comparing different positions of the read text and the position of the eyes, there was a probability of increasing the value of the near vision for the vertical position $\left(\mathrm{UNVA}_{\mathrm{V}}\right)$. The mean values show an increase of near visual acuity in all patients, particularly those with an AL $<22.5 \mathrm{~mm}$. It is believed that, in short eyes with an implanted IOL of higher optical power, the same value of its displacement towards the cornea will cause a higher myopia compared with an IOL that of lower optical power.

\section{Acknowledgements}

The authors would like to thank the entire staff of the Eye Clinic JL FBMI CTU in Prague for their cooperation in this study.

\section{Funding}

No funding was received.

\section{Availability of data and materials}

The input data for the study are summarised in Table I and do not include any direct or indirect identifiers. The datasets generated and analysed in the present study are available from the corresponding author on reasonable request.

\section{Authors' contributions}

MZ conceived, designed and performed the data analysis of this study. MF and JL coordinated preoperative and postoperative examinations of the eyes and made general revisions. SP performed cataract surgery in all the patients and made general revisions of study. All the authors have read and approved the final version of this manuscript for publication.

\section{Ethics approval and consent to participate}

All patients included in the present study provided written informed to participate, and the study protocol conformed to the principles outlined in the Declaration of Helsinki under approval from the ethic committee of JL Clinic FBME CTU in Prague.

\section{Patient consent to publication}

All patients consented to disclose their postoperative condition, visual acuity and eye parameters to be published in the present study.

\section{Competing interests}

The authors state that there are no conflicts of interest regarding the publication of this article.

\section{References}

1. Lešták J, Pitrová Š, Fůs M and Žáková M: The Uncorrected Near Visual Acuity after the Monofocal Intraocular Lens Implantation. Cesk Slov Oftalmol 73: 127-133, 2017 (In Czech).

2. Lister LJ, Suheimat M, Verkicharla PK, Mallen EA and Atchison DA: Influence of Gravity on Ocular Lens Position. Invest Ophthalmol Vis Sci 57: 1885-1891, 2016.

3. Lim DH, Han JC, Kim MH, Chung ES and Chung TY: Factors affecting near vision after monofocal intraocular lens implantation. J Refract Surg 29: 200-204, 2013.

4. Hayashi K, Hayashi H, Nakao F and Hayashi F: Aging changes in apparent accommodation in eyes with a monofocal intraocular lens. Am J Ophthalmol 135: 432-436, 2003.

5. Nanavaty MA, Vasavada AR, Patel AS, Raj SM and Desai TH: Analysis of patients with good uncorrected distance and near vision after monofocal intraocular lens implantation. J Cataract Refract Surg 32: 1091-1097, 2006.

(i) (9) This work is licensed under a Creative Commons EY Attribution-NonCommercial-NoDerivatives 4.0 International (CC BY-NC-ND 4.0) License. 